\title{
The Pitch Invader-COVID-19 Canceled the Game: What Can Science Do for Us, and What Can the Pandemic Do for Science?
}

This was supposed to be a great year for athletes, coaches, sports scientists, and fans. The 4-year Olympic cycle was completing its final stages, and the Tokyo 2020 Olympic Games were on the horizon. UEFA Euro 2020 should have taken us through 12 countries to determine the new European soccer champion in mid-July. Before that, we were supposed to enjoy numerous sporting events across the globe yielding new champions in different sports and competition levels. And then, COVID-19 hit. On March 11, 2020, the World Health Organization declared a pandemic caused by novel coronavirus (COVID-19), triggering unprecedented postponement/cancellation of sporting events around the globe, including the summer Olympic Games. Just as in the final minutes of a game a naked "streaker," a "pitch invader," runs across the field with security personnel in pursuit, causing the game to be disrupted and bringing frustration and misery to our faces, COVID-19 brought sport, and much more in daily human life, to a halt.

Although sporting events have been canceled in the past due to wars and disease outbreaks, this is the first time that the magnitude of its impact has been so large. The 1916 Olympics was canceled due to the outbreak of World War I, but fortunately, the pandemic influenza of 1918-1919 was largely resolved prior to the Antwerp Olympiad of 1920. The 1940 and 1944 Olympics (and other major sporting championships) were disrupted by World War II. However, despite continuing social disruptions, certainly including rampant diseases, the London 1948 Olympiad was successfully contested. Due to foot-and-mouth disease (2001), the Six Nations Championships in rugby was postponed, and in 2003, the SARS outbreak caused the FIFA Women's World Cup to be relocated from China to the United States. The Ebola virus epidemic in 2014 and 2015 caused numerous sporting events in Africa to be canceled and/or relocated, while Zika virus appeared as a major threat to the Rio 2016 Olympiad. However, no pandemic so far has caused such massive and widespread cancelations of sporting events globally as COVID-19. The spread of the virus was extremely fast and reached pandemic status shortly after the first case (circa late November to December 2019) had been detected in Wuhan, China. Most of the affected countries were prompt in implementing public health measures to "flatten the curve" (reducing the early rate of infections and thus preventing medical intensive-care units from being overwhelmed with acutely ill patients). These restrictive measures affected the world of sports very hard, as "social distancing" is basically the primary option for disease mitigation when there are no effective medical therapies or vaccines.

For the world of sport, the social protocols instituted in response to the COVID-19 epidemic present several problems. These include loss of revenue, disruption of athletic careers, and the inability to train and practice normally. Can sport science provide answers that will help us understand, and perhaps minimize, the impact of COVID-19? For the past 50 years or so, sport science has been able to contribute to competitive sport, even though sometimes we feel like practice and science are worlds apart. ${ }^{1}$ However, as this pandemic is unprecedented in modern history, this time there might be more questions than answers.

The specific situation caused by COVID-19 pandemic has provided us a unique opportunity for getting deeper insight into several phenomena that have been the topic of our interest for years, such as detraining, ${ }^{2}$ cross-training, ${ }^{3,4}$ or short-term periodization, ${ }^{5}$ and tapering. ${ }^{6}$ Even though the current situation will not allow us to use well-designed and adequately controlled experimental methods, data collection and analysis of physiological and performance changes, essentially Mother Nature's experiment, can help us understand many things about training and performance. Detraining effects in soccer players, for example, are mostly evaluated during the transition period, which is often relatively short and not always completely passive. ${ }^{2}$ Unfortunately, it looks like this pandemic will substantially prolong this transition period and narrow the options that can be used to stay active during the pandemic. So, there has been a large sample of top-level athletes who, unwillingly, have been trapped in this "experimental" condition. Observing the detraining changes in top-level athletes, who generally have reached the limits of human potential, can be informative not only for sport but for health, as well.

From the beginning of March 2020, almost all sporting activities have been stopped. Public health restrictions have affected sports differently as they have imposed different disruptions to normal training practices. Team-sport athletes were deprived of their skill-based sessions, and endurance athletes lost their modality of training as many were not allowed to use public sporting areas (e.g., swimmers were not allowed to use public pools). Almost instantly athletes turned their homes into gyms and started improvising training activities to maintain their capacity. Resistance-training programs have typically comprised body-weight exercises combined with kettlebells and dumbbells or any other objects found at home, which limits the potential to improve strength/power. ${ }^{7}$ In addition, because of restrictions on social interaction, athletes have been forced to conduct training programs alone and unsupervised, which may negatively influence optimal intensity distribution and fitness improvement. ${ }^{8,9}$ On this basis, detraining ${ }^{2}$ and loss of training specificity ${ }^{3,4}$ become significant issues to coaches and athletes. Depending on the length of the lockdown, as well as the improvisation/creativity of training strategies, detraining effects can be highly variable among athletes, sports, and countries. Although science can provide us with a fair share of answers to detraining effects resulting from insufficient short $^{10}$ and long-term ${ }^{11}$ training stimulus, these can hardly be translated to the COVID-19 pandemic situation, in which athletes have been forced to train in isolation and with limited supervision, in limited facilities, and, most important, with uncertainty about the length of such conditions and their final outcomes.

Similar only to sporting disruptions caused by wars, restoration of top-level sport performance will be influenced by a complex interplay of all sport-science disciplines, sport physiology with greater emphasis on exercise immunology, sport psychology and 
sociology, sport nutrition, sports medicine, epidemiology, and public health, all of which need to be fine-tuned for us to enjoy high-quality competitive sport again in the near future. Even though the current scientific evidence suggests that physiological and performance losses can be restored in a few weeks of retraining after a short-term detraining, ${ }^{2,10}$ the mental consequences that might occur after the pandemic might slow things down a little bit. ${ }^{11,12}$ Indeed, this pandemic has emerged as a new major stressor that influences mental health. ${ }^{13}$ It is therefore of the utmost importance that during this time of crisis, as well as after the crisis, athletes be viewed through multidisciplinary lenses and treated with consideration on all biopsychosocial factors relevant to their well-being and mental health. ${ }^{14}$ Restoration of full competition performance and ability to compete at the highest level in these conditions is a clear challenge, which has to be achieved with absolute consideration of an integrated, multifactorial periodization approach. ${ }^{15}$

Health is the most valuable thing a person has and is a primary prerequisite for top-level athletic performance. Therefore, return to sporting events after such activity-disrupting events should be accomplished with a sharp focus on protecting the athletes' health. ${ }^{15-17}$ However, during the pandemic, professional-sport financial stakeholders have urged sporting bodies to resume competition activities as soon as possible and are anxious to see athletes train again, even during the peak of the pandemic. ${ }^{18}$ In many places, and considering the economic impact of television coverage, there was even pressure to resume competition in empty stadiums despite the fact that possible premature reactivation of sport activities might have negative public health and personal health consequences. With the pressure provided by professional player and media contracts and the public's desire for sport as entertainment, the urge to resume competition can be large enough to increase the risk of players being infected, as well as contribute to further spreading of disease among others. This is particularly dangerous as a prolonged presymptomatic and postsymptomatic period of infectiveness has been recognized for COVID-19. To protect an entire team, it is advisable for team medical staff to establish a dedicated screening protocol to guide the decisionmaking process regarding return to play. Standardized "return to activity" screening protocols adapted to the COVID-19 pandemic all need to be invented from scratch.

Unfortunately, many athletes have tested positive for COVID-19. Even though epidemiological data indicate that older people with underlying comorbid diseases, including obesity, are at greater risk of developing adverse clinical outcomes with COVID19 that does not mean that athletes cannot develop severe respiratory complications, as well. ${ }^{19}$ Moreover, a greater prevalence of upper respiratory tract infections in athletes has been already established, and at the moment of writing this editorial, we do not know if these populations of athletes were at higher risk of disease deterioration and progression once they have been infected. However, the increased ventilation with exercise presents the possibility for an increased alveolar loading of virus particles, as well as a bigger "cloud" of shed viral particles around an exercising athlete. Both conditions could be relevant to athletic populations. In addition, recent studies indicate that aside from respiratory complications, COVID-19 might generate serious complications related to cardiovascular ${ }^{20}$ and nervous systems ${ }^{21}$ that might lead to hospitalization and even death. Obviously, practicing physical activity during the asymptomatic phase of illness or premature return to sporting activities, especially to heavy training after the infection, could have large implications for disease management. Given the absence of standardized guidelines for return to play after infection, a more conservative approach has been advised. ${ }^{19}$ However, another very important question for athletes is whether restoration of full fitness and performance capacities after disease cessation could be somehow compromised, and by how much, depending on the level of disease severity.

These are all pending questions to which we will need answers in the near future. It will take time for us to learn more about the influence of such pandemics on all aspects of athletes' lives, whether general health or specific training and performance. Will sporting careers need to be sacrificed for some athletes to stay healthy? On the other hand, how long will it take to get to the previous level of performance? Our thoughts go to those who had the Tokyo Olympic Games in sight as the last important competitive event in their careers and for whom the COVID-19 pandemic "destroyed their dreams" of eventually finishing on an Olympic podium. We hope that they will be able to lengthen their training plans by one additional year of training and competition.

Multidisciplinary approaches built by combining different disciplines of sport science will be required to identify the new needs of athletes. A variety of guidelines are emerging in the literature, many of them based on soccer, the biggest competitive sporting activity in the world. ${ }^{16,18,22-25}$ Hopefully, they will form the basis of understanding how to return to play in the most expeditious manner possible. Challenging times and opportunities are ahead for us all.

Daniel Bok, University of Zagreb, Croatia

Karim Chamari, IJSPP Associate Editor, Qatar Orthopedic and Sports Medicine Hospital, Qatar

Carl Foster, IJSPP Editor Emeritus, University of Wisconsin-La Crosse, USA

\section{References}

1. Buchheit M. Houston, we still have a problem. Int J Sports Physiol Perform. 2017;12(8):1111-1114. PubMed ID: 28714760 doi:10. 1123/ijspp.2017-0422

2. Silva JR, Brito J, Akenhead R, Nassis GP. The transition period in soccer: a window of opportunity. Sports Med. 2016;46(3):305-313. PubMed ID: 26530720 doi:10.1007/s40279-015-0419-3

3. Brearley S, Bishop C. Transfer of training: how specific should we be? Strength Cond J. 2019;41(3):97-109. doi:10.1519/SSC. 0000000000000450

4. Foster C, Hector LL, Welsh R, Schrager M, Green MA, Snyer AC. Effects of specific and cross-training on running performance. Eur $J$ Appl Physiol Occup Physiol. 1995;70(4):367-372. doi:10.1007/ BF00865035

5. Hartmann H, Wirth K, Keiner M, Mickel C, Sander A, Szilvas E. Short-term periodization models: effects on strength and speedstrength performance. Sports Med. 2015;45(10):1373-1386. PubMed ID: 26133514 doi:10.1007/s40279-015-0355-2

6. Vachon A, Berryman N, Mujika I, Paquet JB, Arvisais D, Bosquet L. Effects of tapering on neuromuscular and metabolic fitness in team sports: a systematic review and meta-analysis [published online ahead of print March 14, 2020]. Eur J Sports Sci. doi:10.1080/17461391. 2020.1736183

7. Suchomel TJ, Nimphius S, Bellon CR, Stone MH. The importance of muscular strength: training considerations. Sports Med. 2018; 48(4):765-785. PubMed ID: 29372481 doi:10.1007/s40279-018$0862-\mathrm{z}$ 
8. Foster C, Heimann KM, Esten PL, Brice G, Porcari JP. Differences in perceptions of training by coaches and athletes. $S$ Afr J Sports Med. 2001;8(2):3-7.

9. Coutts AJ, Murphy AJ, Dascombe AJ. Effect of direct supervision of a strength coach on measures of muscular strength and power in young rugby league players. J Strength Cond Res. 2004;18(2):316323. PubMed ID: 15142000 doi:10.1519/R-12972.1

10. Mujika I, Padilla S. Detraining: loss of training-induced physiological and performance adaptations. Part 1: short term insufficient training stimulus. Sports Med. 2000;30(2):79-87. PubMed ID: 10966148 doi:10.2165/00007256-200030020-00002

11. Mujika I, Padilla S. Detraining: loss of training-induced physiological and performance adaptations. Part 2: long term insufficient training stimulus. Sports Med. 2000;30(3):145-154. PubMed ID: 10999420 doi:10.2165/00007256-200030030-00001

12. Mahase E. Covid-19: mental health consequences of pandemic need urgent research, paper advises. BMJ. 2020;369:m1515. PubMed ID: 32299806 doi:10.1136/bmj.m1515

13. Reardon CL, Hainline B, Miller Aron C, et al. Mental health in elite athletes: International Olympic Committee consensus statement (2019). Br J Sports Med. 2019;53(11):667-699. PubMed ID: 31097450 doi:10.1136/bjsports-2019-100715

14. Homles EA, O'Connor RC, Perry VH, et al. Multidisciplinary research priorities for the COVID-19 pandemic: a call for action for mental health science. Lancet Psychiatry. 2020;7(6):547-560. doi:10.1016/S2215-0366(20)30168-1

15. Mujika I, Halson S, Burke LM, Balagué G, Farrow D. An integrated, multifactorial approach to periodization for optimal performance in individual and team sports. Int J Sports Physiol Perform. 2018;13(5): 538-561. PubMed ID: 29848161 doi:10.1123/ijspp.2018-0093

16. NSCA.com. COVID-19-return to training. 2020.

17. Mann RH, Clift BC, Boykoff J, Bekker S. Athletes as community; athletes in community: Covid-19, sporting mega-events and athlete health protection [published online ahead of print April 17, 2020]. Br J Sports Med. doi:10.1136/bjsports-2020-102433

18. Corsini A, Bisciotti GN, Eirale C, Volpi P. Football cannot restart soon during the COVID-19 emergency! A critical perspective from the Italian experience and call for action [published online ahead of print March 24, 2020]. Br J Sports Med. doi:10.1136/bjsports-2020102306

19. Hull JH, Loosemore M, Schwellnus M. Respiratory health in athletes: facing the COVID-19 challenge [published online ahead of print April 8, 2020]. Lancet Respir Med. doi:10.1016/S2213-2600(20) 30175-2

20. Bonow RO, Fonarow GC, O'Gara PT, Yancy CW. Association of coronavirus disease 2019 (COVID-19) with myocardial injury and mortality [published online ahead of print March 27, 2020]. JAMA Cardiol. doi:10.1001/jamacardio.2020.1105

21. Jin H, Hong $\mathrm{C}$, Chen $\mathrm{S}$, et al. Consensus for prevention and management of coronavirus disease 2019 (COVID-19) for neurologists [published online ahead of print April 1, 2020]. Stroke Vasc Neurol. doi:10.1136/svn-2020-000382

22. Hughes D, Saw R, Panagodage Perera NK, et al. The Australian Institute of Sport Framework for Rebooting Sport in a COVID-19 Environment [published online ahead of print May 6, 2020]. J Sci Med Sport. doi:10.1016/j.jsams.2020.05.004

23. Munoz MD, Meyer T. Infectious diseases and football-lessons not only from COVID-19. Sci Med Football. 2020;4:85-86. doi:10.1080/ 24733938.2020.1749422

24. Timplea T. Sports health during the SARS-Cov-2 pandemic [published online ahead of print May 2, 2020]. Sports Med. doi:10.1007/ s40279-020-01288-7

25. Toresdahl BD, Asif IM. Coronavirus disease 2019: considerations for the competitive athlete. Sports Health. 2020;12:221-224. PubMed ID: 32250193 doi: $10.1177 / 1941738120918876$ 